\title{
LASER-INDUCED PHOTOCHEMICAL REACTION OF MALEIC ACID SOLUTIONS IN THE PRESENCE OF HYDROGEN PEROXIDE
}

\author{
YUICHI SHIMIZU ${ }^{1}$, SHUN'ICHI SUGIMOTO ${ }^{2}$, \\ SHUNICHI KAWANISHI ${ }^{1}$ and NOBUTAKE SUZUKI ${ }^{3}$
Osaka Laboratory for Radiation Chemistry, Japan Atomic Energy Research Institute, Mii-Minami 25-1, Neyagawa, Osaka 572, Japan

(Received 20 November 1996)

Targeting the selective and direct synthesis of tartaric acid (TA), the photochemical reactions of maleic acid (MA) solutions containing $\mathrm{H}_{2} \mathrm{O}_{2}$ in various solvents have been investigated using four wavelengths in the UV region between 193 and $351 \mathrm{~nm}$, with high intensity from an excimer laser. All the laser irradiations in $\mathrm{H}_{2} \mathrm{O}$ resulted in the direct synthesis of TA with lower selectivity and it was found that, with XeF-laser $(351 \mathrm{~nm})$ irradiation in 1,4-dioxane, TA is selectively and directly synthesized from MA containing $\mathrm{H}_{2} \mathrm{O}_{2}$ of lower concentration at room temperature. On the other hand, none of the irradiations in methanol, N,N-dimethylformamide, acetonitrile, and tetrahydrofuran gave the selective formation of TA. On the basis of these results, the reaction scheme for the selective formation of TA is discussed.

Keywords: Organic photosynthesis; excimer laser; tartaric acid; selectivity; wavelength effects; solvent effects

\section{INTRODUCTION}

Since the beams of the UV region emitted from an excimer laser are monochromatic and of high intensity and, moreover, their photon

\footnotetext{
${ }^{1}$ Present address: Kansai Research Establishment, Japan Atomic Energy Research Institute, Mii-Minami 25-1, Neyagawa, Osaka 572, Japan.

${ }^{2}$ Present address: Radiation Application Development Association, Osaka Laboratory for Radiation Chemistry, Mii-Minami 25-1, Neyagawa, Osaka 572, Japan.

${ }^{3}$ Present address: Japan Synchrotron Radiation Research Institute, Kanaji 1503-1 Kamigori, Hyogo 678-12, Japan.
} 
energies are nearly comparable to the bond energy of some organic compounds [1], they enable efficient formation of a desired active species with high density for organic chemical reactions. Therefore, the application of the laser in organic chemical reactions is a promising methodology for the direct and selective synthesis of valuable compounds [2]. From such viewpoints, many studies on the laserinduced organic chemical reactions have been carried out [3]. As an example, as reported previously, we found that diols are directly and selectively synthesized by the laser irradiation of $\mathrm{N}_{2}$-saturated alcohols containing $\mathrm{H}_{2} \mathrm{O}_{2}$ [4], and demonstrated that more reactive hydroxyl radicals are easily and purely formed with high density by excimerlaser irradiation of $\mathrm{H}_{2} \mathrm{O}_{2}$ because of the high intensity compared with the case of UV lamp irradiation $[4,5]$.

Tartaric acid (TA) is very important as an intermediate for the manufacture of medicines, and also in the food industry. At present, TA is industrially manufactured by a very complex synthetic method from tartar [6]. In laboratories, it is mainly prepared by oxidizing maleic acid (MA) using osmium tetraoxide [7, 8]. However, the catalyst is poisonous and expensive, furthermore, prolonged reaction time is required for this process. For these reasons, a simpler, more rapid, and practical methodology for the synthesis of TA was eagerly sought $[8,9]$. The above process newly developed by us is a selective and direct formation route of the hydroxyl group which is a useful functional group and may be applicable to some compounds such as alkene as a selective and direct introduction method of the hydroxyl group in the double bond. We have, therefore, attempted to induce efficiently the addition of the hydroxyl radicals formed by laserphotolysis of $\mathrm{H}_{2} \mathrm{O}_{2}$ to the double bond in MA, for the purpose of the selective and direct synthesis of valuable compounds such as TA containing a hydroxyl group. On the other hand, the laser-induced photochemical reaction of an aqueous solution of MA has been investigated from the viewpoint of chemistry in excited molecular electronic states relative to nonlinear laser chemistry $[10,11]$, these studies showed that the basic process is cis-trans isomerization leading to the formation of fumaric acid (FA) with the dimerization, etc. However, there is as yet very little information on the study of the laser-induced photochemical reaction of MA for the synthesis of more valuable compounds. We, therefore, have investigated in detail the 
effects of reaction conditions, especially the effects of $\mathrm{H}_{2} \mathrm{O}_{2}$ feeding rate, wavelength of laser beams and solvents, on the formation of TA from MA. In this paper, we report a new method for the direct and selective synthesis of TA from MA initiated by XeF laser-photolysis of $\mathrm{H}_{2} \mathrm{O}_{2}$.

\section{EXPERIMENTAL}

All chemicals were of reagent grade. MA and all solvents such as 1,4dioxane (DO), methanol (MeOH), N,N-dimethylformamide (DMF), acetonitrile $(\mathrm{MeCN})$, and tetrahydrofuran (THF) were purchased from Nakalai Tesque Co., Ltd., and from Tokyo Kasei Kogyo Co., Ltd., respectively, and were used without further purification. These solvents and distilled water were selected from the viewpoint that they all dissolve MA at room temperature, and also are miscible with aqueous $\mathrm{H}_{2} \mathrm{O}_{2}$. Furthermore, all these solvents show absorption bands in the wavelength range shorter than $300 \mathrm{~nm}$. The $30 \%$ aqueous solution of $\mathrm{H}_{2} \mathrm{O}_{2}$ was purchased from Santoku Chemical Industries Co., Ltd. $\mathrm{N}_{2}$ used was of high purity grade of above $99.9 \%$.

The laser-induced reactions were carried out in a Pyrex glass cylindrical reaction vessel (volume: $91.5 \mathrm{ml}$, diameter: $35.5 \mathrm{~mm}$, light pathlength: $70 \mathrm{~mm}$ ) with a Suprasil window (diameter: $45 \mathrm{~mm}$, thickness: $3 \mathrm{~mm}$ ) for the incidence of laser beams. Water, DO, and their mixtures, $\mathrm{MeOH}, \mathrm{DMF}, \mathrm{MeCN}$, and THF solutions of MA were placed in the reaction vessel, respectively, and well-bubbled with $\mathrm{N}_{2}$ in order to remove oxygen. The $\mathrm{N}_{2}$-saturated solution of MA was stirred magnetically $(500 \mathrm{rpm})$, and mainly irradiated with the XeF laser (Lumonics Hyper EX-460, wavelength: $351 \mathrm{~nm}$, pulse energy: $80 \mathrm{~mJ}$ per pulse, frequency: $16 \mathrm{~Hz}$, pulse duration: $12-15 \mathrm{~ns}$, beam shape: $9 \times$ $34 \mathrm{~mm}$ ) at room temperature. At the same time with irradiation, a $30 \%$ aqueous solution of $\mathrm{H}_{2} \mathrm{O}_{2}$ was added to the solutions of MA with the feeding rate from 3.4 to $13.1 \mathrm{ml} \mathrm{h}^{-1}$ by using a microfeeder (Atto Corp., AC-2120). The quantity of light from the lasers was determined by using a calorimeter (Scientech 38-4UV5). The calorimeter was also placed behind the reaction vessel to determine precisely the quantity of light absorbed in the system during the laser irradiation. Furthermore, for the experiments of wavelength effects on the photochemical 
reaction, especially the formation of TA, ArF (wavelength: $193 \mathrm{~nm}$, energy: $2.4 \mathrm{~W}$ ), $\mathrm{KrF}$ (wavelength: $248 \mathrm{~nm}$, energy: $2.9 \mathrm{~W}$ ), $\mathrm{XeCl}$ (wavelength: $308 \mathrm{~nm}$, energy: $2.1 \mathrm{~W}$ ), and $\mathrm{XeF}$ (wavelength: $351 \mathrm{~nm}$, energy: $2.2 \mathrm{~W}$ ) lasers were used with irradiation of an aqueous solution of MA containing $\mathrm{H}_{2} \mathrm{O}_{2}$.

Analyses were mainly carried out by ion chromatography (Yokogawa IC-100, SAX1 column, length: $25 \mathrm{~cm}$, two) and by gas chromatography (Shimadzu GC-3BT, Molecular sieve 5A column and $\mathrm{GC}-4 \mathrm{C}$, Porapak N column) for gaseous products. A gas chromatograph-mass spectrometer (Shimadzu QP-5000, DB-1 column) was also used. The UV absorption spectra were recorded with a Shimadzu spectrophotometer (UV-2100). The $\mathrm{pH}$ of the solutions before and after the irradiation was obtained by measurements with a Horiba $\mathrm{pH}$ meter (F-15).

\section{RESULTS}

$\mathrm{H}_{2} \mathrm{O}_{2}$ has an absorption band in the wavelength around $350 \mathrm{~nm}$, while MA does not have it in that range. So, firstly, the XeF laser $(351 \mathrm{~nm})$ was used as the source of beam absorbed by $\mathrm{H}_{2} \mathrm{O}_{2}$ but not by MA, to avoid the decomposition of MA. In fact, when the $\mathrm{N}_{2}$-saturated aqueous solution of MA alone was irradiated in the absence of $\mathrm{H}_{2} \mathrm{O}_{2}$, organic products were hardly produced even on irradiation for $45 \mathrm{~min}$, indicating that the decomposition does not occur. On the other hand, as shown in Figure 1, when the $\mathrm{N}_{2}$-saturated aqueous solution of MA was irradiated with the $\mathrm{XeF}$ laser at $\mathrm{H}_{2} \mathrm{O}_{2}$ feeding rate of $3.6 \mathrm{ml} \mathrm{h}^{-1}$, glycolic acid (GA) was produced as the main product together with TA, FA, oxalic, succinic, and malic acids as minor products, and small amounts of gaseous products such as $\mathrm{H}_{2}, \mathrm{CO}$, and $\mathrm{CO}_{2}$ etc. In sharp contrast to XeF-laser irradiation, negligible amounts of TA were detected by irradiation with UV light (mainly 366 and $334 \mathrm{~nm}$, ca. 13 $\mathrm{mW} / \mathrm{cm}^{2}$ ) from an $\mathrm{Hg}$ lamp obtained through the UV filter (Toshiba UV-33 and UV-D33S), even on irradiation for ca. $20 \mathrm{~h}$. It was found from these results that the quantity of TA was much larger in the laser irradiation than in the lamp irradiation. This indicates that the laser irradiation is more favorable for the efficient formation of TA although the wavelength and the irradiation dose of the laser beams 


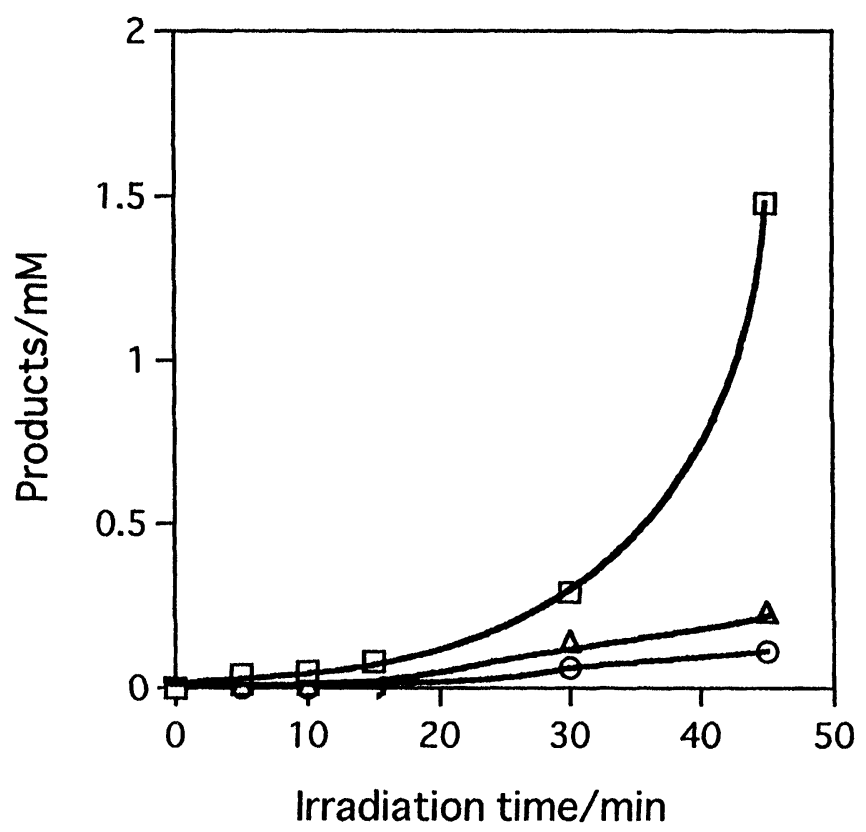

FIGURE 1 Plots of the quantities of main products as a function of irradiation time. Aqueous $30 \% \mathrm{H}_{2} \mathrm{O}_{2}$ feeding rate: $3.6 \mathrm{ml} \mathrm{h}^{-1}$. $\square: \mathrm{GA}, \bigcirc: \mathrm{TA}, \triangle$ : malic acid.

are almost the same as those of the UV light. For this reason, it can be considered that the light intensity per unit time is about $10^{7}$ times larger with the laser than with the lamp, i.e., high intensity for the laser, as described already. Also, as shown in Figure 1, the quantity of TA gradually increases with irradiation time, while the quantity of GA increases steeply and quadrically with time, giving the quantum yield of ca. 0.1 for $45 \mathrm{~min}$ irradiation. The selectivity of TA formation of 45 min irradiation was about $6 \%$. In contrast, at $\mathrm{H}_{2} \mathrm{O}_{2}$ feeding rate of $13.1 \mathrm{ml} \mathrm{h}^{-1}$, the selectivity of TA was very much smaller $(<1 \%)$. Thus, it was revealed that TA formation is favorable in lower $\mathrm{H}_{2} \mathrm{O}_{2}$ feeding rate. Furthermore, the selectivity of TA formation in this reaction was smaller and the main product was GA, not TA. However, GA is also a series of hydroxy acids, which are obtained via the monoor dihydroxylation of MA in this system, in analogy with TA. Moreover, as judged from the structural formula, it may be presumed that GA is a secondary product resulting from the decomposition by 
the laser-reirradiation with the high intensity of TA once formed in this reaction. From this viewpoint, in an attempt to suppress the secondary decomposition of TA, the effects of the wavelengths of laser beams on the formation of hydroxy acids, including TA, were examined next, using the fourth wavelengths of the UV region of 193 to $351 \mathrm{~nm}$ from the excimer laser.

Table I shows the wavelength effects on the quantities of main products from an aqueous solution of MA by ArF-, KrF-, XeCL-, and XeF-laser irradiations for $45 \mathrm{~min}$ at $\mathrm{H}_{2} \mathrm{O}_{2}$ feeding rate of $3.8 \mathrm{ml} \mathrm{h}^{-1}$. In the case of ArF-laser (193 nm) irradiation, GA is the main product, and the selectivity of TA formation was about $6 \%$, similarly with the $\mathrm{XeF}$ irradiation. However, the combined selectivity of hydroxy acid was about $72 \%$, much lower than in the case of $\mathrm{XeF}$ irradiation $(92 \%)$. On the other hand, in KrF-laser $(248 \mathrm{~nm})$ irradiation, FA formed by the isomerization via the direct absorption excitation of MA is the main product (selectivity, ca. 50\%), and the selectivity of TA was nearly zero. Also, in XeCl-laser $(308 \mathrm{~nm}$ ) irradiation, FA formed by the isomerization via the two-photon absorption excitation of MA was the main product (selectivity, ca. 46\%) although the quantity of TA was the largest among the wavelengths used, and the combined selectivities of hydroxy acid for both KrF- and XeCL-laser irradiations were below $50 \%$. In sharp contrast, a very high combined selectivity of hydroxy acid in XeF-laser irradiation indicates that only negligible amounts of products other than hydroxylated products of MA are produced. From these results, it was apparent that laserinduced photochemical reactions of an aqueous solution of MA containing $\mathrm{H}_{2} \mathrm{O}_{2}$ are significantly affected by the wavelengths of laser

TABLE I Comparison of the quantities of products under the laser irradiations ${ }^{\mathrm{a}}$

\begin{tabular}{lllll}
\hline Product & $\mathrm{XeF}$ & $\mathrm{ArF}$ & $\mathrm{KrF}$ & $\mathrm{XeCl}$ \\
\hline GA & 1.48 & 5.73 & 0.86 & 2.22 \\
TA & 0.11 & 0.65 & 0.01 & 1.76 \\
FA & 0.03 & 0.02 & 3.55 & 3.81 \\
Malic acid & 0.23 & 1.07 & 2.64 & 0 \\
Succinic acid & 0 & 1.56 & 0 & 0 \\
Oxalic acid & 0.08 & 1.35 & 0.13 & 0.46 \\
\hline
\end{tabular}

a [Product]: $\mathrm{mM}$, irradiation time: $45 \mathrm{~min}, \mathrm{H}_{2} \mathrm{O}_{2}$ feeding rate: $3.8 \mathrm{ml} \mathrm{h}^{-1}$. 
beams, indicating the usefulness of the XeF laser for the efficient formation of the hydroxylated products including TA.

As mentioned above, it has been confirmed that an efficient formation of the hydroxylated products is strongly dependent on the wavelengths of laser beams. However, the results of the wavelength effects suggest that the laser-induced secondary decomposition of TA once formed is not necessarily responsible for the formation of GA, and that the effects of other reaction conditions must also be taken into consideration for the formation. We, therefore, examined the effects of solvents on the selective formation of TA as a reaction factor, using the $\mathrm{XeF}$ laser. Here, $\mathrm{DO}$ in the place of $\mathrm{H}_{2} \mathrm{O}$, a polar solvent, was used as a nonpolar solvent under the solvent selection conditions previously described in the experimental section in this text. Figure 2 shows the quantities of main products from a solution of MA

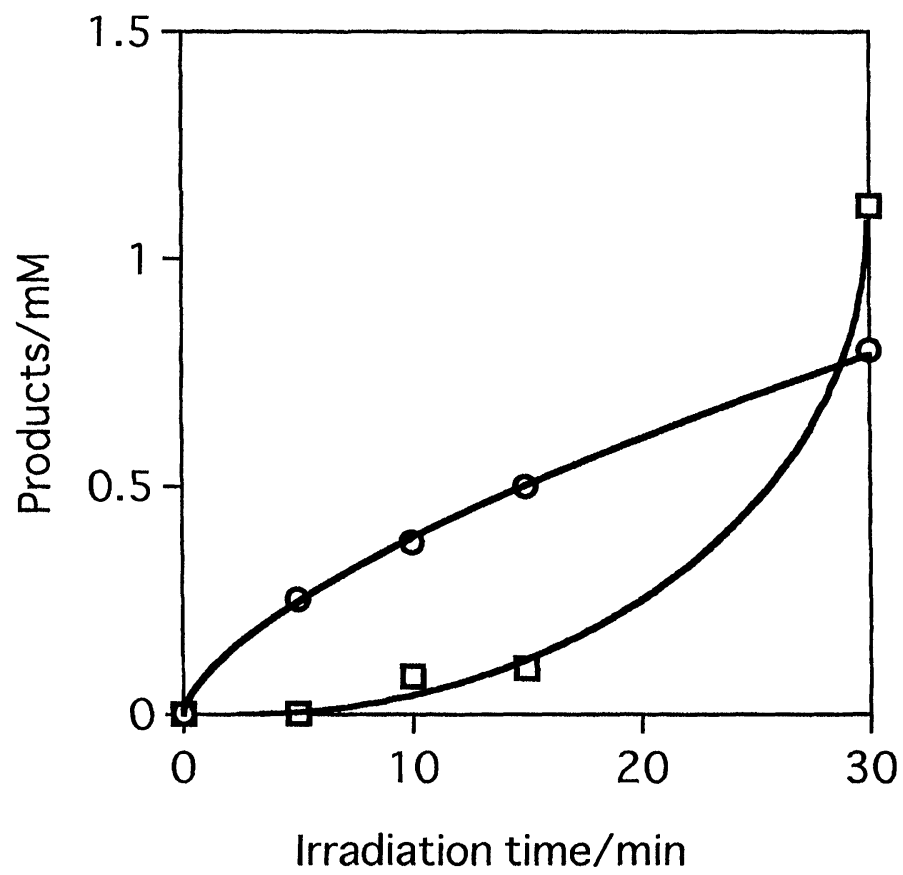

FIGURE 2 Relationship between the quantities of main products in DO with irradiation time. Aqueous $30 \% \mathrm{H}_{2} \mathrm{O}_{2}$ feeding rate: $3.4 \mathrm{ml} \mathrm{h}^{-1} . \square: \mathrm{GA}, \bigcirc: \mathrm{TA}, \triangle$ : malic acid. 
in DO by XeF-laser irradiation as a function of irradiation time at $\mathrm{H}_{2} \mathrm{O}$ feeding rate of $3.4 \mathrm{ml} \mathrm{h}^{-1}$. As shown, only negligible amounts of products other than GA and TA were observed even on irradiation for $45 \mathrm{~min}$ ( $\mathrm{pH}$ value of the reaction mixture after $45 \mathrm{~min}$ was ca. 6.7). It is noteworthy that the quantity of TA increases with time up to about 30 min, and that is much greater than that of GA obtained within 25 min. The selectivity of TA formation was 76 and $73 \%$ for 10 - and 15 -min irradiation, respectively, in sharp contrast to $6 \%$ in $\mathrm{H}_{2} \mathrm{O}$. Moreover, from the comparison of Figure 1 with Figure 2, it was seen that the quantity of TA in DO is much larger than that in $\mathrm{H}_{2} \mathrm{O}$. Thus, it was found that TA is selectively and directly synthesized by XeF-laser irradiation of MA containing lower concentration of $\mathrm{H}_{2} \mathrm{O}_{2}$ in $\mathrm{DO}$ at room temperature.

The above result suggests that the polarity of solvents is an important factor for the selective formation of TA. So, in order to confirm this point, a series of experiments were carried out using mixed solvents of DO and $\mathrm{H}_{2} \mathrm{O}$ having various compositions and polar solvents other than $\mathrm{H}_{2} \mathrm{O}$. As shown in Table II, the addition of DO to $\mathrm{H}_{2} \mathrm{O}$ resulted in rapid elevation of TA selectivity which further elevated with increasing fraction of DO. Moreover, as shown in Table III, in $\mathrm{MeOH}$ the selectivity was almost the same as that in $\mathrm{H}_{2} \mathrm{O}$, in sharp contrast to DO. Similarly, neither DMF, MeCN, nor THF showed sensitization of TA selectivity compared with that in $\mathrm{H}_{2} \mathrm{O}$. Consequently, these results evidently indicate that the selective and efficient formation of TA is more favorable in nonpolar solvents than in polar solvents.

TABLE II Effects of DO fraction on the selectivity of TA formation by XeF-laser irradiation in DO- $\mathrm{H}_{2} \mathrm{O}$ mixed solvents $^{\mathrm{a}}$

\begin{tabular}{cc}
\hline DO fraction vol\% & TA selectivity mol\% \\
\hline 0 & 6 \\
25 & 7 \\
50 & 20 \\
75 & 24 \\
100 & 76 \\
\hline
\end{tabular}

${ }^{a}$ Irradiation time: 10 min, $\mathrm{H}_{2} \mathrm{O}_{2}$ feeding rate: $3.4 \mathrm{ml} \mathrm{h}^{-1}$ 
TABLE III Solvent effects on the selectivity of TA formation by XeF-laser irradiation ${ }^{\mathrm{a}}$

\begin{tabular}{lc}
\hline Solvent & TA selectivity \\
\hline $\mathrm{H}_{2} \mathrm{O}$ & 6 \\
$\mathrm{DO}$ & 76 \\
$\mathrm{MeOH}$ & 4 \\
$\mathrm{DMF}$ & 3 \\
$\mathrm{MeCN}$ & 2 \\
THF & 3 \\
\hline
\end{tabular}

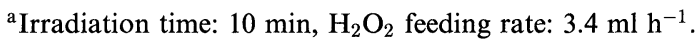

\section{DISCUSSION}

$\mathrm{H}_{2} \mathrm{O}_{2}$ showed a broad absorption band in the wavelength range $(190 \sim 350 \mathrm{~nm})$ shorter than $350 \mathrm{~nm}$, on the other hand, the absorption band of MA was shorter than $300 \mathrm{~nm}$. It can be, therefore, considered that the initiating species of TA formation in this system using laser beams ranging in wavelength from 193 to $351 \mathrm{~nm}$ is $\bullet \mathrm{OH}$ formed efficiently by the laser-photolysis of $\mathrm{H}_{2} \mathrm{O}_{2}$ [4, 12]. In fact, in $\mathrm{XeF}$-laser irradiation, the formation of TA including GA is suppressed by the addition of the thiocyanate ion which is an efficient scavenger of -OH [13]. Therefore, it is considered that TA is produced through the addition of two $\bullet \mathrm{OH}$ to the double bond in MA. However, in ArF-, $\mathrm{KrF}$-, and $\mathrm{XeCL}-$ laser irradiations, since not only $\mathrm{H}_{2} \mathrm{O}_{2}$ but also MA absorbs their beams, the reactions such as the isomerization [10] via a direct excitation process of MA would occur during the irradiation. In practice, in $\mathrm{KrF}$-laser irradiation, the formation of FA is the main process, also via the two-photon absorption for XeCl-laser irradiation, as shown in Table I. Moreover, in ArF-laser irradiation, since all MA, $\mathrm{H}_{2} \mathrm{O}_{2}$, and products once formed by the irradiation absorb the beam, their laser-induced secondary photochemical reactions would also proceed during the irradiation. The results that an extremely small quantity of FA was produced and there was lack of the product selectivity compared with $\mathrm{KrF}$ - and $\mathrm{XeCl}$-laser irradiations most probably support this consideration.

Furthermore, the results that the formation of TA competes with that of GA which is a similar hydroxylated products of MA, as shown in Figure 2, and their formations are strongly affected by the solvent 
rather than the wavelength suggest that TA and GA are competitively produced through a common intermediate formed in the route to the hydroxylation of MA. It seems reasonable to consider that the monohydroxylated radical formed by the addition of one $\bullet \mathrm{OH}$ to $\mathrm{MA}$ is the common intermediate to produce TA and GA competitively. On the other hand, the quantity of TA gradually decreased with increasing $\mathrm{H}_{2} \mathrm{O}_{2}$ feeding rate, the increase of $\mathrm{H}_{2} \mathrm{O}_{2}$ concentration accompanying rapid increases in the quantity of GA, suggesting the occurrence of such decomposition as bond cleavage of the intermediate by excess $\mathrm{H}_{2} \mathrm{O}_{2}$ to produce GA predominantly. It is generally known that the double bond is subject to cleavage in prolonged reaction time using excess reagent, for example $\mathrm{H}_{2} \mathrm{O}_{2}$, in hydroxylation [14]. It may be, therefore, considered that the bond cleavage of the intermediate is caused by the protonic species such as $\mathrm{H}^{+}$and/or $\mathrm{H}_{3} \mathrm{O}^{+}$resulting from $\mathrm{H}_{2} \mathrm{O}_{2}$ remaining in the system, following the formation of GA and the decomposition such as decarboxylation shown by the formations of $\mathrm{CO}, \mathrm{CO}_{2}$ etc. Similarly, it can be considered that the property of $\mathrm{H}_{2} \mathrm{O}$ as a protogenic solvent, i.e., $\mathrm{H}^{+}$release, is responsible for the lower selectivity of TA formation in an aqueous solution. Moreover, this may be applied to the reaction in $\mathrm{MeOH}$ which also is a protogenic solvent. On the contrary, the selective and efficient formation of TA was achieved by the reaction in DO, an aprotic solvent [15]. This result and the fact that the addition of DO in $\mathrm{H}_{2} \mathrm{O}$ remarkably elevates TA selectivity support the above consideration, namely, that in the presence of media such as protogenic solvents and $\mathrm{H}_{2} \mathrm{O}_{2}$ which release easily $\mathrm{H}^{+}$and this class, TA selectivity is lowered on account of the decomposition of the intermediate leading to the formation of TA by $\mathrm{H}^{+}$released from the media (Scheme 1 ). This reaction scheme may be also supported by the behavior of a quadrical formation of GA while that for TA formation is not quadrical, as shown in Figures 1 and 2. On the other hand, the large difference in the behavior of TA formations in DO and THF, grouped into the same ether solvents, may be mainly explained by the following data: THF is more reactive to $\bullet \mathrm{OH}$ than DO [16] and also, much more than $\mathrm{MeOH}$ [17] and, consequently, this effect results in the larger decrease of the hydroxylated products in THF. Furthermore, all the reactions in polar solvents were more disadvantageous than those in nonpolar ones for the selective formation of TA. In this regard, it may be considered 

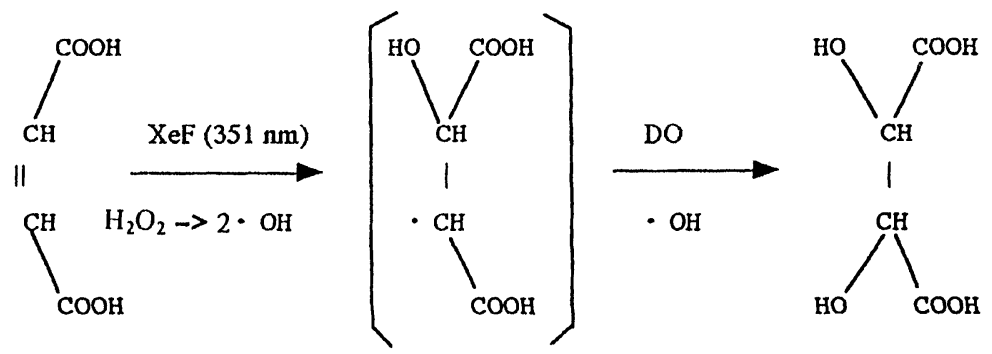

MA

$$
\begin{array}{r}
\mathrm{H}_{2} \mathrm{O} \\
\text { etc. }
\end{array}
$$

TA

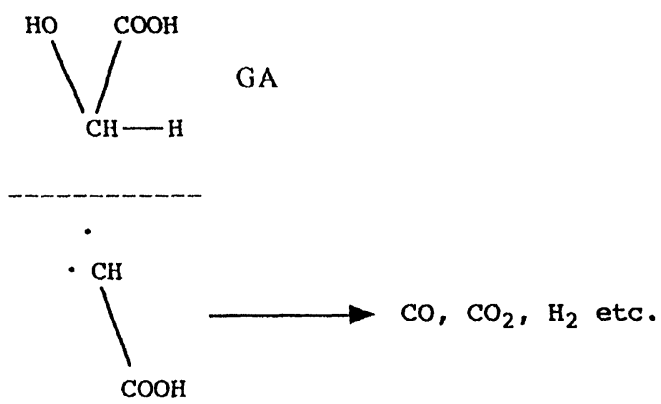

that, since the main reaction of TA formation proceeds via a radical mechanism, the reaction is of greater advantage in nonpolar solvents than in polar solvents such as not only $\mathrm{MeOH}, \mathrm{H}_{2} \mathrm{O}$ and THF but also $\mathrm{DMF}$ and $\mathrm{MeCN}$ which are most useful in ionic reactions [18].

\section{References}

[1] Brau, Ch. A. (1979). Topics in Applied Physics, Excimer Lasers, ed. Rhodes Ch. K. (Springer-Verlag, Berlin) 30, pp. 87.

[2] Rhodes, Ch. K. and Hoff, P. W. (1979). [1] pp. 175; Springer Series in Optical Sciences, High-Power Lasers and Applications, eds. Kompa, K.-L. and Walther, H. (Springer-Verlag, Berlin, 1979); Yabe, A. (1989), Sai Sentan Reza Kako Gijutsu (in Japanese), ed. H. Kawatsura (CMC, Tokyo), pp. 143.

[3] Dauben, W. G. and Phillips, R. B. (1982). J. Am. Chem. Soc., 104, 5780.

[4] Shimizu, Y., Sugimoto, S., Kawanishi, S. and Suzuki, N. (1991). Bull. Chem. Soc. Jpn., 64, 3607. 
[5] Shimizu, Y., Sugimoto, S., Kawanishi, S. and Suzuki, N. (1989). Chem. Lett., 2153.

[6] Yamamoto, Y. (1990). Yuki Gosei Kagaku (in Japanese), 48, 71.

[7] Schroder, M. (1980). Chem. Rev., 80, 187.

[8] Shing, T. K. M., Tai, V. W.-F and Tam, E. K. W. (1994). Angew. Chem. Int. Ed. Engl., 33, 2312.

[9] C\$EN, 5 Dec., 1994, pp. 23.

[10] Khoroshilova, E. V., Kuzmina, N. P., Letokhov, V. S. and Matveetz, Yu. A. (1983). Appl. Phys., B31, 145.

[11] Leupold, D., Ehlert, J., Oberlander, S., Klose, E., Mory, S. and Winkelmann, G. (1989). Laser Chem., 10, 73.

[12] Zellner, R., Exner, M. and Herrmann, H. (1990). J. Atoms. Chem., 10, 411.

[13] Milas, N. A. and Sussman, S. (1937). J. Am. Chem. Soc., 59, 2345.

[14] For example, Byers, A. and Hickinbottom, W. J. (1948). J. Chem. Soc., 284, 1328.

[15] Tokura, N. (1972). Yobai Wa, Kagaku Dojin, Kyoto, pp. 53 (in Japanese).

[16] Dagaut, P., Liu, R., Walington, T. J. and Kurylo, M. J. (1990). J. Phys. Chem., 94, 1881.

[17] Ravishankara, A. R. and Davis, D. D. (1978). J. Phys. Chem., 82, 2852.

[18] For example, Bhattacharyya, D. N., Smid, J. and Szwarc, M. (1965). J. Phys. Chem., 69, 624. 